Quim. Nova, Vol. 28, No. 6, 1014-1022, 2005

\title{
PARÂMETROS TERMODINÂMICOS DA REAÇÃO DE ADSORÇÃO DE BORO EM SOLOS TROPICAIS ALTAMENTE INTEMPERIZADOS
}

\author{
Marcio Roberto Soares e Luís Reynaldo Ferracciú Alleoni* \\ Departamento de Solos e Nutrição de Plantas, Escola Superior de Agricultura "Luiz de Queiroz", \\ Universidade de São Paulo, CP 9, 13418-900 Piracicaba - SP \\ José Carlos Casagrande \\ Departamento de Recursos Naturais e Proteção Ambiental, Centro de Ciências Agrárias, \\ Universidade Federal de São Carlos, CP 153, 13600-970 Araras - SP
}

Recebido em 13/10/04; aceito em 10/3/05; publicado na web em 10/8/05

\begin{abstract}
THERMODYNAMIC PARAMETERS FOR BORON ADSORPTION REACTION ON HIGHLY WEATHERED TROPICAL SOILS. The driving force of boron adsorption on some tropical soils was evaluated by means of thermodynamic parameters. The batch method was employed, and the reaction was monitored at different $\mathrm{pH}$ values. The Langmuir equation successfully fitted the experimental results and provided reasonable isotherm parameters. Boron adsorption increased as a function of the $\mathrm{pH}$ of the soil solution and the concentration of added boron. The reaction was favorable and proceeded spontaneously, being strongly exoergic, as indicated by a negative free energy $(\Delta \mathrm{G})$ and a separation factor $\left(K_{R}\right)<1$. The boron adsorption phenomenon and the soilsolution interface were thermodinamically described using a theoretical model.
\end{abstract}

Keywords: tropical soils; boron; adsorption.

\section{INTRODUÇÃO}

O boro é um elemento semi-metálico, considerado um micronutriente que atende aos critérios de essencialidade ao pleno desenvolvimento vegetal ${ }^{1}$. Seu comportamento químico é muito similar ao do silício e relativamente simples quando comparado com o de outros oxiânions ${ }^{2}$. Ao contrário de outros elementos com um número reduzido de elétrons e grande número de orbitais disponíveis para ligação química, aliado ao seu alto potencial de ionização, o boro elementar não é encontrado na natureza, porque está sempre combinado com o oxigênio para a formação de compostos covalentes. Espécies $\mathrm{B}_{2} \mathrm{O}_{3}$ normalmente reagem com água para formar o ácido bórico $\left[\mathrm{B}(\mathrm{OH})_{3}\right]$, que atua como ácido fraco, tendendo a formar íons $\mathrm{B}(\mathrm{OH})_{4}^{-}$pela incorporação de uma hidroxila à sua molécula ${ }^{3}$. A reação de formação do hidroxiborato é espontânea, mas em solução aquosa, o boro existe quase que exclusivamente sob a forma não dissociada de ácido bórico, devido à sua pequena constante de dissociação $\left(\mathrm{p} K_{\mathrm{a}}=9,2\right)^{4}$. Em decorrência da neutralidade elétrica de sua forma predominante $\left[\mathrm{B}(\mathrm{OH})_{3}{ }^{0}\right.$, o boro é um elemento extremamente móvel no solo e pode ser facilmente lixiviado. Fitotoxicidade por boro pode ocorrer por práticas inadequadas de fertilização, de irrigação e de aplicação de outros insumos agrícolas que contêm boro, tais como herbicidas e inseticidas. Mais recentemente, o descarte de resíduos efluentes de indústrias que empregam o ácido bórico e sais de borato na manufatura de vidros, de esmaltes cerâmicos e de ligas metálicas, tem aumentado o potencial de entrada do boro na cadeia alimentar humana, em concentrações que podem causar sérios riscos à saúde ${ }^{5}$, o que torna importante se conhecer o comportamento químico do boro sob os pontos de vista agronômico e ambiental.

Quando o boro é liberado dos minerais do solo, mineralizado da matéria orgânica ou adicionado ao solo por meio de irriga-

*e-mail: 1rfalleo@esalq.usp.br ção, fertilização ou descarte de resíduos, parte do elemento permanece na solução do solo e parte é adsorvida pela fase sólida do solo ${ }^{6}$. A mineralogia do adsorvente desempenha uma importante função na intensidade e no mecanismo de adsorção do boro $^{7,8}$, sendo que constituintes do solo capazes de adsorvê-lo incluem os óxidos metálicos de $\mathrm{Fe}, \mathrm{Al}$ e $\mathrm{Mn}$, minerais de argila e matéria orgânica. A caulinita reage mais intensamente com boro que a illita, enquanto a facilidade de formação de complexos orgânicos de ácido bórico com grupos diol dos ácidos carboxílicos explica porque a fração humificada é a principal fonte de boro do solo9. Óxidos e hidróxidos de Fe e Al são importantes componentes de solos altamente intemperizados dos trópicos úmidos e adsorvem grandes quantidades de boro ${ }^{10}$. $\mathrm{O}$ boro pode interagir com estes minerais ou por processos químicos eletrostáticos, com suas superfícies ionizáveis, em função do caráter anfótero dos grupos de superfície, ou por complexação de superfície, a qual é considerada um ligante ${ }^{3}$. A adsorção específica é determinada tanto pela natureza dos ânions quanto pelo tipo de grupo funcional da superfície dos colóides, e é mais pronunciada em solos que contêm grandes quantidades de óxidos de $\mathrm{Fe}$ e Al. O boro é especificamente adsorvido por complexos de esfera interna ("inner-sphere") de alta energia, pelo mecanismo de troca de ligantes entre o elemento e os grupos hidroxilados (Al-OH, Fe-OH, Al- $\mathrm{OH}_{2}$ e $\mathrm{FeOH}_{2}$ ) que estão coordenadamente ligados às superfícies das partículas ${ }^{7}$.

Grande parte da pesquisa sobre previsão da mobilidade e do destino de elementos que se apoiou em informações termodinâmicas da reação de adsorção, foi conduzida com espécies catiônicas de elementos potencialmente tóxicos. Embora numerosas, as informações sobre a adsorção aniônica raramente vêm acompanhadas por uma descrição mais aprofundada, embasada termodinamicamente. Parâmetros termodinâmicos podem ser derivados de experimentos isotermicamente conduzidos, mas sua aplicação para outras condições é controvertida. Alguns autores restringiram o uso destes parâmetros apenas para as condições em que o experi- 
mento foi conduzido ${ }^{11}$, enquanto outros realçaram que a vantagem da obtenção destes parâmetos, a partir de modelos, reside no fato de sua ampla aplicação, porque estes valores são derivados de constantes de equilíbrio e podem ser considerados valores padrão ${ }^{12}$. No entanto, os valores dos parâmetros termodinâmicos derivados de modelos provavelmente diferirão daqueles medidos diretamente por métodos calorimétricos ${ }^{12}$. A distribuição do boro entre as fases líquida e sólida é uma medida da posição de equilíbrio no processo de adsorção e o estado deste sistema pode ser definido por um conjunto de propriedades termodinâmicas, tais como as variações da energia livre de Gibbs $(\Delta \mathrm{G})$, que podem servir como medidas da extensão da reação de adsorção ${ }^{13}$.

Solos ácricos ocorrem em paisagens antigas e planas, algumas delas da região norte do estado de São Paulo, onde ocupam cerca de $170.000 \mathrm{ha}^{14}$. O termo ácrico vem do grego akros, que significa "no fim", e qualifica um solo próximo do final do seu ciclo de desenvolvimento, ou seja, extremamente intemperizado. O interesse por estes solos justifica-se principalmente, pelo predomínio dos óxidos de $\mathrm{Fe}$ e $\mathrm{Al}$ na sua composição mineralógica. $\mathrm{O}$ processo mais importante da formação do solo ácrico é a intensa perda de sílica (dessilicatização), com resultante acúmulo de óxidos insolúveis, como os de ferro (hematita) e os de alumínio (gibbsita), além da caulinita, que é um mineral de argila do tipo 1:1. Nas camadas subsuperficiais destes solos, o ponto de efeito salino nulo (PESN), que é o valor de $\mathrm{pH}$ para o qual a carga e o potencial elétrico superficiais de um sistema reversível são nulos, pode superar o $\mathrm{pH}$ original, o que confere um balanço de carga positivo, notadamente em profundidades maiores que $0,5 \mathrm{~m}$, onde a matéria orgânica praticamente não atua. $\mathrm{O}$ objetivo deste trabalho foi estudar os parâmetros termodinâmicos da reação de adsorção de boro em solos com predomínio de óxidos de $\mathrm{Fe}$ e $\mathrm{Al}$ em sua mineralogia e avaliar a força direcional desta reação pelo estudo da variação da energia livre sob diferentes condições de $\mathrm{pH}$.

\section{PARTE EXPERIMENTAL}

\section{Solos}

Foram utilizadas amostras superficiais e subsuperficiais de dois solos ácricos extremamente intemperizados, um Latossolo Vermelho (LV) e um Latossolo Amarelo (LA), com caráter eletropositivo em subsuperfície, e de um Nitossolo Vermelho (NV), com balanço negativo de cargas ao longo de todo o perfil do solo, derivados de basalto e representativos da região norte do estado de São Paulo (Ribeirão Preto - 21¹0'39'S, 4748'37'W; Guaíra - 20¹9'06”S, $48^{\circ} 18^{\prime} 38^{\prime \prime}$ ). Para estudo da adsorção de boro em função da variação do $\mathrm{pH}$ do solo, as amostras foram incubadas até $\mathrm{pH}$ constante após receberem doses crescentes de carbonato de cálcio e de ácido clorídrico $^{15}$.

\section{Caracterização dos solos}

A caracterização química das amostras para fins de levantamento foi feita em amostras de terra fina seca ao ar (TFSA), passadas em peneira de malha de $2 \mathrm{~mm}^{16,17}$. Os teores de carbono orgânico (CO) foram quantificados por oxidação da matéria orgânica com dicromato de potássio, na presença de ácido sulfúrico. $\mathrm{O}$ excesso de $\mathrm{K}_{2} \mathrm{Cr}_{2} \mathrm{O}_{7}$ foi titulado com íons $\mathrm{Fe}^{2+}$, obtidos a partir de uma solução padronizada de sulfato ferroso amoniacal. $\mathrm{O} \mathrm{pH}$ foi potenciometricamente determinado em supensões de $\mathrm{H}_{2} \mathrm{O}$ e de $\mathrm{KCl}$ $1 \mathrm{~mol} \mathrm{~L}^{-1}$ com relação solo:solução 1:2,5, e a diferença $\Delta \mathrm{pH}=\mathrm{pH}_{\mathrm{MKCl}}$ $-\mathrm{pH}_{\mathrm{H} 2 \mathrm{O}}$ foi usada como estimativa do balanço de cargas ${ }^{18}$. Cátions básicos $(\mathrm{CB})$ foram extraídos por resina trocadora de íons, sendo
Ca e Mg determinados por espectrofotometria de absorção atômica e $\mathrm{Na}$ e $\mathrm{K}$ por fotometria de emissão por chama. O alumínio trocável foi extraído por solução de cloreto de potássio $1 \mathrm{~mol} \mathrm{~L}^{-1} \mathrm{e}$ determinado por titulação com hidróxido de amônio $0,025 \mathrm{~mol} \mathrm{~L}^{-1}$. A capacidade de troca cationica efetiva foi estimada pelo método da soma $\left(\mathrm{CTC}_{\mathrm{e}}=\mathrm{CB}+\mathrm{Al}\right)$. Os teores de $\mathrm{Fe}, \mathrm{Al}$ e $\mathrm{Si}$, associados aos minerais secundários, foram determinados no extrato sulfúrico (relação 1:20 solo:solução $\mathrm{H}_{2} \mathrm{SO}_{4} 9 \mathrm{~mol} \mathrm{~L}^{-1}$ ) e expressos na forma de óxidos para cálculo do índice de intemperização pela relação molar $\mathrm{Ki}=\mathrm{SiO}_{2} / \mathrm{Al}_{2} \mathrm{O}_{3}$. Formas cristalinas e pouco cristalinas de óxidos de $\mathrm{Fe}$ e $\mathrm{Al}$ foram extraídas por soluções de ditionito-citratobicarbonato de sódio (DCB-Na) e de oxalato ácido de amônio (reagente de Tamm), respectivamente. O ponto de efeito salino nulo (PESN) representou o valor de $\mathrm{pH}$ no ponto de intersecção das curvas de titulação com $\mathrm{H}^{+}$e com $\mathrm{OH}^{-}$, em três concentrações de $\mathrm{KCl}\left(0,1 ; 0,01 \text { e } 0,001 \mathrm{~mol} \mathrm{~L}^{-1}\right)^{14}$. Após a saturação das amostras com $\mathrm{CsCl}$, a densidade de cargas foi calculada pela quantificação das cargas permanentes $\left(\sigma_{\mathrm{o}}\right)$ e variáveis $\left(\sigma_{\mathrm{H}}\right)$, com base na seletividade do Cs pelas cavidades siloxanas dos minerais de argila 2:1, que é maior que pelas superfícies ionizáveis dos óxidos de $\mathrm{Fe}$ e Al e das bordas quebradas dos minerais de argila $1: 1^{19}$. A análise granulométrica foi feita pelo método da pipeta $^{20}$, que se baseia na velocidade de decantação das diferentes partículas do solo, enquanto o método BET de adsorção de $\mathrm{N}_{2}$ foi empregado para medida da área superficial específica $(\mathrm{ASE})^{21}$. Os teores de caulinita e de gibbsita foram estimados por análise térmica diferencial $(\mathrm{ATD})^{22}$.

\section{Isotermas de adsorção}

Experimentos de adsorção em batelada foram conduzidos para determinar a quantidade de boro adsorvido. A 2,0 g de TFSA foram adicionados $20 \mathrm{~mL}$ de solução de $\mathrm{NaCl} 0,01 \mathrm{~mol} \mathrm{~L}^{-1}$ contendo quantidades crescentes de boro $(0,0 ; 0,1 ; 0,2 ; 0,4 ; 0,8 ; 1,2 ; 1,6 ; 2,0$ e $\left.4,0 \mu \mathrm{g} \mathrm{mL}^{-1}\right)$, na forma de ácido bórico. $\mathrm{O}$ conjunto foi acondicionado em frascos de polietileno e colocado sob agitação (150 osc $\min ^{-1}$ ) por $24 \mathrm{~h}$, a $24 \pm 2^{\circ} \mathrm{C}$. A suspensão foi filtrada, e a concentração de boro remanescente no sobrenadante foi determinada pelo método colorimétrico da azometina- $\mathrm{H}^{23}$. A quantidade de boro adsorvido $\left(\mathrm{q}_{\mathrm{eq}}\right)$ e a porcentagem de adsorção (\%) foram computados pelas seguintes relações:

$q_{e q}=\frac{\left[\left(C_{0}-C_{e q}\right) V\right]}{X}$

adsorção $(\%)=\frac{\left(\mathrm{C}_{0}-\mathrm{C}_{\text {eq }}\right)}{\mathrm{C}_{0}} \times 100$

em que $\mathrm{q}_{\mathrm{eq}}$ é a quantidade de boro adsorvido após o equilíbrio ( $\mu \mathrm{g}$ $\left.\mathrm{g}^{-1}\right) ; \mathrm{C}_{0} \mathrm{e} \mathrm{C}_{\mathrm{eq}}$ as concentrações inicial adicionada e a de equilíbrio $\left(\mu \mathrm{g} \mathrm{mL} \mathrm{m}^{-1}\right)$, respectivamente; $\mathrm{V}=$ volume da solução $(\mathrm{mL})$ e $\mathrm{X}=$ massa da amostra de terra $(\mathrm{g})$. A quantidade de boro originalmente presente nas amostras, apesar de pequena, foi descontada no cálculo da quantidade de boro adsorvido.

Isotermas de adsorção foram construídas a partir dos resultados experimentais, e a adsorção de boro foi comparada com aquela estimada pela forma não linear da isoterma de Langmuir:

$q_{\text {eq }}=\frac{K C_{e q} q_{\text {max }}}{1+K C_{e q}}$

em que K é o parâmetro relacionado com a afinidade do solo pelo boro $\left(\mu \mathrm{L} \mu \mathrm{g}^{-1}\right)$ e $\mathrm{q}_{\max }$, a máxima capacidade de adsorção de boro 
$\left(\mu \mathrm{g} \mathrm{g}^{-1}\right)$. A isoterma de Langmuir foi ajustada aos resultados de adsorção de boro pelos programas Fitfun.bas e Fitfunc ${ }^{24}$, que empregam a otimização não-linear dos quadrados mínimos e não exigem a linearização da isoterma, o que evita tanto a introdução de mudanças na distribuição dos erros quanto a aquisição de parâmetros influenciados $\left(\mathrm{K} \text { e } \mathrm{q}_{\text {máx }}\right)^{7}$.

\section{Parâmetros termodinâmicos da reação de adsorção}

Estudos sobre a termodinâmica da reação de adsorção consideram a atividade do elemento em vez da concentração, para obtenção da constante de equilíbrio termodinâmica padrão $\left(\mathrm{K}_{\mathrm{c}}^{\circ}\right)$ do sistema ${ }^{25}$ :

$\mathrm{K}_{\mathrm{c}}^{\circ}=\frac{\mathrm{a}_{\mathrm{ads}}}{\mathrm{a}_{\mathrm{sol}}}$

em que $a_{\text {ads }}$ e $a_{\text {sol }}$ representam a atividade da espécie química na fase adsorvida e em solução, respectivamente.

Neste experimento, os coeficientes de atividade foram considerados unitários devido à baixa concentração do soluto $(0 \mathrm{a} 4 \mu \mathrm{g}$ $\left.\mathrm{mL}^{-1} \mathrm{~B}\right)$ e à força iônica desprezível do eletrólito suporte $(0,01 \mathrm{~mol}$ $\left.\mathrm{L}^{-1}\right)^{25}$, como prevê a equação de Debye-Hückel ${ }^{26}$. A atividade, a, está relacionada com a concentração, $C$, pela expressão:

$a=\gamma \pm C$

e sendo o coeficiente médio de atividade iônica, $\gamma \pm$, igual à unidade, a Equação 4 pode ser reescrita $\operatorname{como}^{25,27,28}$ :

$\mathrm{K}_{\mathrm{eq}}=\frac{\mathrm{q}_{\mathrm{eq}}}{\mathrm{C}_{\mathrm{eq}}}$

em que $\mathrm{K}_{\mathrm{eq}}$ é a constante de equilíbrio termodinâmica aparente do sistema $\left(\mathrm{mL} \mathrm{g} \mathrm{g}^{-1}\right)$.

Com o uso de soluções diluídas, cujos coeficientes de atividade estão próximos da unidade (Equação 5), o sistema segue o modelo de solução idealmente diluída, para o qual os efeitos de interações diferenciadas entre solvente e soluto podem ser desprezados, como assegurado pela lei de Henry. Para estas soluções, a constante de equilíbrio padrão $K_{c}^{o}$ pode ser considerada equivalente a constante de equilíbrio aparente $\left(\mathrm{K}_{\mathrm{eq}}\right)^{28}$.
O contato entre a fase sólida e as espécies presentes em solução pode ocorrer sob condições de equilíbrio ou não ${ }^{26} \mathrm{e}$, em ambos os casos, as reações de adsorção podem ser descritas matematicamente pela determinação da energia livre de Gibbs $^{29-32}$ :

$\Delta \mathrm{G}=\mathrm{RT}\left(\log \mathrm{C}_{\text {eq }}-\log \mathrm{C}_{0}\right)$

em que $\Delta G$ é a variação da energia livre $\left(\mathrm{J} \mathrm{mol}^{-1}\right) ; \mathrm{R}$, a constante universal dos gases, 8,314 $\mathrm{J} \mathrm{mol}^{-1} \mathrm{~K}^{-1}$ e T, a temperatura absoluta $(\mathrm{K})$.

As características da isoterma de Langmuir podem ser expressas em termos do fator de separação ou parâmetro de equilíbrio, $\mathrm{K}_{\mathrm{R}}$, constante adimensional que indica se a reação de adsorção foi favorável ou não, por meio da relação ${ }^{33-35}$ :

$\mathrm{K}_{\mathrm{R}}=\frac{1}{1+\mathrm{K} \mathrm{C}_{0}}$

em que K é a constante de afinidade estimada pela equação de Langmuir (Equação 3).

\section{RESULTADOS E DISCUSSÃO}

\section{Atributos dos solos}

Alguns atributos (eletro)químicos, físicos e mineralógicos dos solos estão contidos na Tabela 1. As amostras subsuperficiais dos Latossolos apresentaram valores de PESN superiores aos do $\mathrm{pH}$ do solo, o que resultou em balanço positivo de cargas, como confirmado pelos valores de $\Delta \mathrm{pH}$. Estes valores estão de acordo com aqueles reportados para solos altamente intemperizados ${ }^{14,18,36} . \mathrm{Em}$ seus primeiros $125 \mathrm{~cm}$ de profundidade, os Latossolos também apresentaram capacidade efetiva de troca de cátions $\left(\mathrm{CTC}_{\mathrm{e}}\right)$ menor que $15 \mathrm{mmol}_{\mathrm{c}} \mathrm{kg}^{-1}$ de argila e $\mathrm{pH}_{\mathrm{KCl}} \geq 5,0$, atendendo aos requisitos para manifestação do caráter ácrico ${ }^{37}$. Estes solos encontram-se próximos do fim do ciclo de desenvolvimento pedogenético. Por conta da ação prolongada do intemperismo, sofreram intensa dessilicatização, refletida pelos baixos valores de Ki. Altas relações $\sigma_{\mathrm{H}} / \sigma_{\mathrm{o}}$ mostraram o predomínio de cargas negativas variáveis nos Latossolos ácricos, o que era esperado, pois os principais constituintes da fase sólida destes solos são matéria orgânica, caulinita e óxidos de $\mathrm{Fe}$ e $\mathrm{Al}$, cuja carga superficial varia de acordo com o $\mathrm{pH}$ e a força iônica do meio.

Tabela 1. Atributos (eletro)químicos, físicos e mineralógicos dos solos estudados.

\begin{tabular}{|c|c|c|c|c|c|c|c|c|c|c|c|c|c|c|c|c|c|c|c|}
\hline \multirow[t]{3}{*}{ Prof. } & \multirow[t]{3}{*}{$\mathrm{pH}_{\mathrm{H} 2 \mathrm{O}}$} & \multirow[t]{3}{*}{$\Delta \mathrm{pH}$} & \multirow[t]{3}{*}{ PESN } & \multirow{2}{*}{\multicolumn{3}{|c|}{$\begin{array}{l}\text { Densidade } \\
\text { de cargas }\end{array}$}} & \multirow{3}{*}{$\mathrm{CTC}_{\mathrm{e}}$} & \multirow[t]{3}{*}{ ASE } & \multirow[t]{3}{*}{ Argila } & \multirow[t]{3}{*}{$\mathrm{CO}$} & \multirow[t]{3}{*}{$\mathrm{Kt}$} & \multirow[t]{3}{*}{$\mathrm{Gb}$} & \multicolumn{6}{|c|}{ Solução extratora } & \multirow[t]{3}{*}{$\mathrm{Ki}$} \\
\hline & & & & & & & & & & & & & \multicolumn{2}{|c|}{ DCB-Na } & \multicolumn{2}{|c|}{ Tamm } & \multicolumn{2}{|c|}{$\mathrm{H}_{2} \mathrm{SO}_{4}$} & \\
\hline & & & & $\sigma_{\mathrm{o}}$ & $\sigma_{\mathrm{H}}$ & $\sigma_{\mathrm{o}} / \sigma_{\mathrm{H}}$ & & & & & & & $\mathrm{Fe}_{\mathrm{d}}$ & $\mathrm{Al}_{\mathrm{d}}$ & $\mathrm{Fe}_{\mathrm{o}}$ & $\mathrm{Al}_{\mathrm{o}}$ & $\mathrm{Fe}_{\text {as }}$ & $\mathrm{Al}_{\mathrm{as}}$ & \\
\hline \multirow{2}{*}{\multicolumn{20}{|c|}{ Nitossolo Vermelho (NV) }} \\
\hline & & & & & & & & & & & & & & & & & & & \\
\hline $0,0-0,2$ & 5,7 & $-0,9$ & 3,6 & 63,1 & 30,2 & 2,1 & 108 & 134 & 820 & 26 & 249 & 59 & 150 & 23 & 12 & 8 & 270 & 167 & - \\
\hline $0,7-0,9$ & 6,0 & $-0,7$ & 3,6 & 35,4 & 30,9 & 1,2 & 54 & 151 & 700 & 7 & 263 & 80 & 150 & 21 & 14 & 7 & 284 & 195 & 0,90 \\
\hline \multicolumn{20}{|c|}{ Latossolo Vermelho (LV) } \\
\hline $0,0-0,2$ & 6,4 & $-0,9$ & 3,6 & 39,9 & 8,2 & 4,9 & 63 & 65 & 600 & 20 & 172 & 375 & 164 & 26 & 13 & 10 & 320 & 195 & - \\
\hline $1,0-1,4$ & 5,3 & $+0,3$ & 5,6 & 16,1 & 4,7 & 3,4 & 8 & 76 & 640 & 5 & 216 & 431 & 185 & 21 & 9 & 7 & 341 & 195 & 0,41 \\
\hline \multicolumn{20}{|c|}{ Latossolo Amarelo (LA) } \\
\hline $0,0-0,2$ & 4,6 & $-0,6$ & 3,4 & 32,3 & 8,4 & 3,8 & 13 & 65 & 350 & 16 & 248 & 200 & 39 & 22 & 2 & 6 & 66 & 91 & - \\
\hline $1,0-1,3$ & 5,1 & $+0,6$ & 6,0 & 18,4 & 1,3 & 14,2 & 3 & 53 & 450 & 6 & 196 & 189 & 43 & 31 & 2 & 8 & 96 & 125 & 0,65 \\
\hline
\end{tabular}

PESN = ponto de efeito salino nulo; $\sigma_{\mathrm{o}}=$ variável; $\sigma_{\mathrm{H}}=$ permanente; $\mathrm{CTC}_{\mathrm{e}}=$ capacidade de troca de cátions efetiva; ASE = área superficial específica; $\mathrm{CO}$ = carbono orgânico; $\mathrm{Kt}=$ caulinita; $\mathrm{Gb}=$ gibbsita; $\mathrm{Fe}_{\mathrm{d}}$ e $\mathrm{Al}_{\mathrm{d}}=$ teores de ferro e de alumínio extraídos em solução DCB-Na (ditionito-citrato-bicarbonato de sódio); $\mathrm{Fe}_{\mathrm{o}}$ e $\mathrm{Al}$ = teores de ferro e de alumínio extraídos em solução de Tamm $\left[(\mathrm{COOH})_{2} \cdot 2 \mathrm{H}_{2} \mathrm{O}+\left(\mathrm{NH}_{4}\right)_{2} \mathrm{C}_{2} \mathrm{O}_{4} \cdot \mathrm{H}_{2} \mathrm{O}\right] ; \mathrm{Fe}_{\text {as }}$ e $\mathrm{Al}_{\text {as }}=$ teores de ferro e de alumínio extraídos pelo ataque com $\mathrm{H}_{2} \mathrm{SO}_{4} 9 \mathrm{~mol} \mathrm{~L}^{-1} ; \mathrm{Ki}^{\circ}=$ índice de intemperização $=\mathrm{SiO}_{2} / \mathrm{Al}_{2} \mathrm{O}_{3}$. 
Atribuiu-se a diminuição dos valores de $\sigma_{\mathrm{H}}$ com a profundidade ao decréscimo dos teores de matéria orgânica, principal gerador de cargas negativas em solos tropicais. $\mathrm{Na}$ ausência da matéria orgânica, os óxidos de $\mathrm{Fe}$ e $\mathrm{Al}$ encarregaram-se de manter cerca de $50 \%$ das cargas reversíveis. Altos valores de cargas permanentes e variáveis foram encontrados no $\mathrm{NV}$, o que lhe rendeu maior densidade de cargas. Isto ocorreu como consequiência do estádio menos avançado de intemperização do NV, cujo valor Ki indicou perda menos intensa de sílica, justificando tanto seus teores maiores de caulinita quanto a ocorrência de minerais de argila do tipo 2:1 (clorita/vermiculita interestratificada e vermiculita) ${ }^{32}$, responsáveis não somente pela manifestação de cargas permanentes, mas também pelo aumento da área superficial específica (ASE). Os teores de gibbsita foram particularmente altos nos Latossolos, e a ocorrência deste mineral tem implicações na magnitude das cargas elétricas, sobretudo nos horizontes mais profundos, onde os teores de CO são menores. Respeitando a proporção de argila dos solos, o $\mathrm{LV}$, por ser o mais intemperizado, apresentou maiores teores de óxidos de Fe cristalinos $\left(\mathrm{Fe}_{\mathrm{d}}\right)$ e amorfos $\left(\mathrm{Fe}_{\mathrm{o}}\right)$, seguido do Nitossolo. Apesar de muito intemperizado, o LA apresentou pequenos teores de óxidos em função do menor conteúdo de argila.

\section{Isotermas de adsorção}

A equação de Langmuir simulou adequadamente os resultados de adsorção de boro (Figura 1). Pequenas diferenças foram notadas entre os resultados obtidos experimentalmente e aqueles estimados pela equação de Langmuir e estes resultados eram esperados, porque a concentrações inferiores a $30 \mu \mathrm{g} \mathrm{mL} \mathrm{mL}^{-1}$ não há registros de desvios da equação de Langmuir ${ }^{38,39}$.

As isotermas não exibiram o clássico comportamento tipo " $L$ ", caracterizado pelo decréscimo da adsorção à medida que a superfície do adsorvente vai se tornando saturada ${ }^{40}$. A aparente inclinação constante (Figura 1) é inerente às isotermas do tipo " $C$ ", que sugerem que o número de sítios disponíveis para adsorção permanece constante ao longo de toda a faixa de concentração do soluto. Isso ocorreu em função das baixas concentrações iniciais de boro $\left(\mathrm{C}_{0}\right)$. Houve aumento da adsorção de boro com a elevação da quantidade inicial adicionada, como já apontado em outros trabalhos ${ }^{41,42}$. Os valores das constantes de Langmuir (Figura1) foram muito semelhantes àqueles encontrados em trabalhos que utilizaram um intervalo semelhante para concentração inicial do elemento. A adsorção máxima de boro, estimada pelo parâmetro $\mathrm{q}_{\max }$ de Langmuir, variou de 37 a $76 \mu \mathrm{g} \mathrm{g}^{-1}$, para as amostras superficiais do LA e do NV, respectivamente (Figura 1). Estes resultados são muito semelhantes àqueles apresentados em alguns trabalhos ${ }^{43,44}$, mas são superiores ao valor mais alto de $\mathrm{q}_{\text {máx }}\left(14 \mu \mathrm{g} \mathrm{g}^{-1}\right)$ encontrado em alguns solos intemperizados brasileiros ${ }^{39}$.

Os maiores valores de $\mathrm{q}_{\text {máx }}$ foram encontrados nas amostras dos horizontes superficiais e podem estar correlacionados com o teor de carbono orgânico (Tabela 1). A matéria orgânica do solo pode adsorver mais boro que os constituintes minerais ${ }^{45,46} . \mathrm{A} \mathrm{q}_{\text {máx }}$ estimada para as amostras dos horizontes subsuperficiais dos dois Latossolos ácricos, principalmente do LA, pode estar associada com o alto valor do PESN que, por ser maior que o $\mathrm{pH}$ do solo, favoreceu o predomínio de cargas positivas, as quais podem atuar na adsorção eletrostática dos poucos ânions borato existentes em condições em que o $\mathrm{pH}$ do solo está distante da primeira constante de dissociação do ácido bórico.

Embora a matéria orgânica favoreça a adsorção de maior quantidade de boro, as constantes K estimadas pelo modelo de Langmuir (Figura 1) sugeriram que o elemento foi mais fortemente adsorvido nos horizontes subsuperficiais, onde a matéria orgânica tem menor
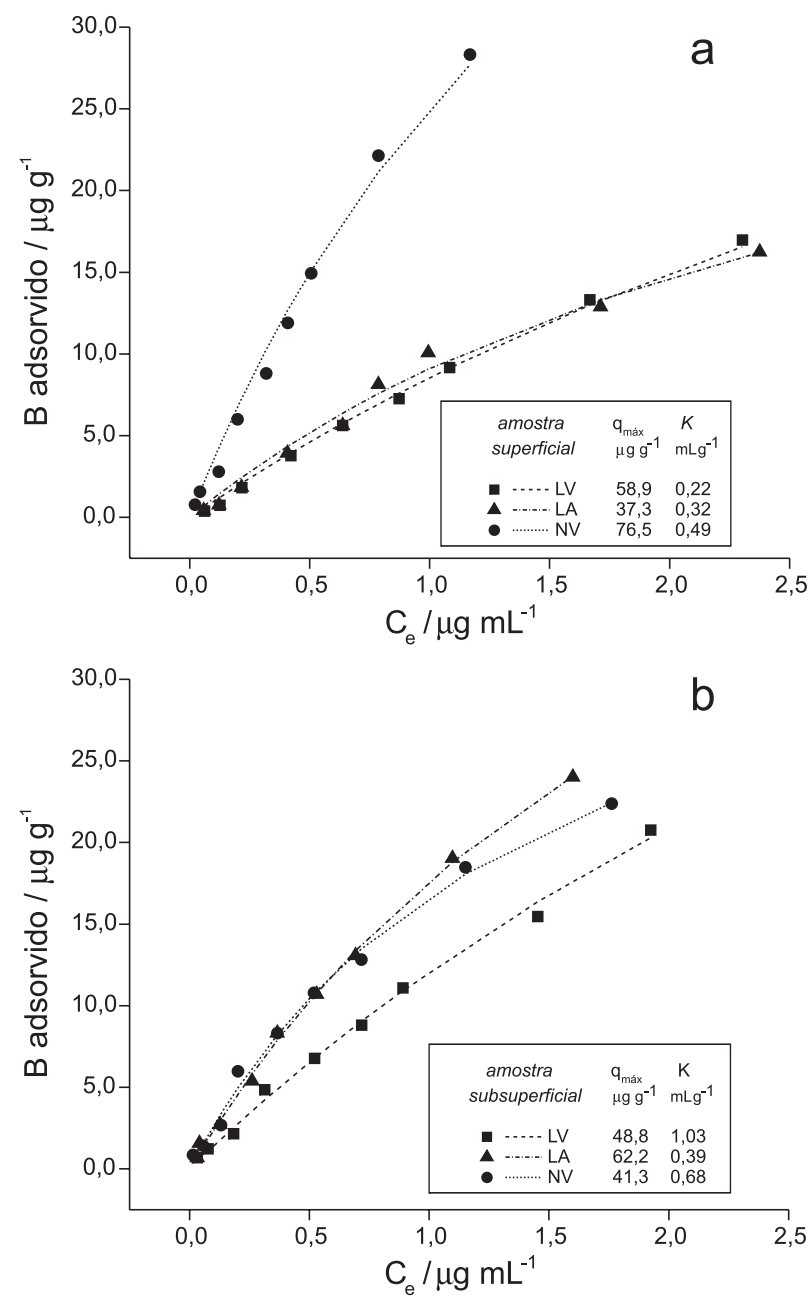

Figura 1. Isotermas de adsorção (curvas) e parâmetros da reação de adsorção de boro ( $q_{\operatorname{máx}}=$ adsorção máxima; $K=$ constante de afinidade) obtidos a partir do ajuste da equação de Langmuir aos resultados experimentais (pontos); $L V=$ Latossolo Vermelho; $L A=$ Latossolo Amarelo; $N V=$ Nitossolo Vermelho

influência e permite maior exposição das superfícies dos colóides minerais, que ficam oclusas nas camadas superficiais do solo em função da estreita associação entre óxidos de $\mathrm{Fe}$ e $\mathrm{Al}$, gibbsita e caulinita com compostos orgânicos.

\section{Influência do pH na adsorção de boro}

A incubação dos solos promoveu uma variação de $\mathrm{pH}$ de 3,9 a 8,0 , influenciando a adsorção de boro. $\mathrm{O}$ pH da solução é um dos principais fatores que afeta a disponibilidade de boro nos $\operatorname{solos}^{2,47}$. A adsorção do elemento aumenta na faixa de $\mathrm{pH}$ entre 3 e 9, próximo ao $\mathrm{pK}_{\mathrm{a}}$ do ácido bórico, e diminui quando o $\mathrm{pH}$ varia de $10 \mathrm{a}$ $11,5^{48}$. A porcentagem de adsorção do boro, medida após a adição de 2,0 $\mathrm{mg} \mathrm{L}^{-1} \mathrm{~B}$, aumentou com a elevação do $\mathrm{pH}$ da solução (Tabela 2). Na amostra superficial do LV, o aumento do $\mathrm{pH}$ de 4,8 para 7,9 resultou em aumento de $35 \%$ na adsorção de boro, sendo que, no maior $\mathrm{pH}$, cerca de $80 \%$ do boro adicionado foi adsorvido. Aumentos de $33 \%$ na adsorção de boro após a aplicação de $\mathrm{CaCO}_{3}$ foram observados em solos paulistas ${ }^{49}$.

Quando o pH variou de 7 a 8, a adsorção de boro aumentou de forma intensa (Tabela 2), principalmente nos Latossolos ácricos. À medida que o $\mathrm{pH}$ se aproxima do $\mathrm{pK}_{\mathrm{a}}$ do ácido bórico, há o aumento 
Tabela 2. Constante de equilíbrio $\left(\mathrm{K}_{\mathrm{eq}}\right)$, variação da energia livre $(\Delta \mathrm{G})$ e proporção de boro adsorvido com a variação de $\mathrm{pH}$ dos solos, após a adição de 2,0 mg L $\mathrm{L}^{-1}$ de boro (LV=Latossolo Vermelho; $\mathrm{LA}=$ Latossolo Amarelo; NV=Nitossolo Vermelho)

\begin{tabular}{lccccc}
\hline solo & $\begin{array}{c}\text { camada } \\
\mathrm{m}\end{array}$ & $\mathrm{pH}$ & $\begin{array}{c}\mathrm{K}_{\mathrm{eq}} \\
\mu{\mathrm{L} \mathrm{g}^{-1}}\end{array}$ & $\begin{array}{c}\Delta \mathrm{G} \\
\mathrm{J} \mathrm{mol}^{-1}\end{array}$ & $\begin{array}{c}\mathrm{B} \text { adsorvido } \\
\%\end{array}$ \\
\hline $\mathrm{LV}$ & $0-0,2$ & 4,8 & 8,47 & -660 & 45,9 \\
& & 5,6 & 13,75 & -931 & 57,9 \\
& & 7,9 & 43,32 & -1801 & 81,2 \\
\cline { 2 - 6 } & $1,0-1,4$ & 5,4 & 12,43 & -869 & 55,4 \\
& & 7,1 & 14,04 & -944 & 58,8 \\
& & 8,0 & 22,26 & -1260 & 69,0 \\
\hline LA & $0-0,2$ & 5,0 & 10,13 & -753 & 50,3 \\
& & 6,0 & 10,32 & -763 & 50,8 \\
& & 7,9 & 18,39 & -1123 & 64,8 \\
\cline { 2 - 6 } & $1,0-1,3$ & 4,4 & 16,34 & -1042 & 62,0 \\
& & 4,9 & 18,84 & -1140 & 65,3 \\
& & 6,1 & 23,24 & -1292 & 69,9 \\
\hline NV & $0-0,2$ & 4,2 & 17,20 & -1077 & 63,2 \\
& & 5,2 & 21,80 & -1245 & 68,6 \\
& & 5,9 & 29,55 & -1480 & 74,7 \\
\cline { 2 - 6 } & $0,7-0,9$ & 3,9 & 16,42 & -1045 & 62,2 \\
& & 5,9 & 17,90 & -1104 & 64,2 \\
& & 7,8 & 37,21 & -1670 & 78,8 \\
\hline
\end{tabular}

das espécies hidroboratos, negativamente carregadas. Como o PESN dos óxidos de $\mathrm{Fe}$ e de $\mathrm{Al}$ é alto, nestas condições de $\mathrm{pH}$ ainda há o predomínio de cargas elétricas positivas, que podem atuar na adsorção eletrostática pela formação de complexos de esfera externa ("outersphere”). O mecanismo de adsorção específica é reconhecidamente o de maior importância na retenção de boro, mas o elemento pode se ligar a minerais de $\operatorname{argila}^{7}$ ou a óxidos de $\mathrm{Fe}^{8}$ pelo mecanismo de esfera externa. Apesar de a proporção das espécies aniônicas ainda ser pequena, sua adsorção é favorecida porque, em $\mathrm{pHs}$ próximos da neutralidade, a concentração de íons hidroxila ainda não exerce efeito competitivo com os ânions borato. Com o aumento do $\mathrm{pH}$, os óxidos de $\mathrm{Al}$ podem tornar-se importantes superfícies adsorventes de boro ao precipitarem-se na forma de $\mathrm{Al}(\mathrm{OH})_{3}$, principalmente no $\mathrm{LV}$, que possui teores maiores de $\mathrm{Al}$ que o LA (Tabela 1).

\section{Abordagem termodinâmica}

\section{Descrição do sistema}

A aplicação da termodinâmica na descrição de um fenômeno requer a seleção do sistema de estudo, o que significa isolar parte do universo de interesse até um nível de restrição que não permita a transferência de energia para o meio que o circunda. Em condições de campo, o solo se comporta como um sistema muito dinâmico, e a necessidade de isolar o sistema somente é atendida sob condições controladas de laboratório. Para fins didáticos, o solo é considerado um sistema composto pelas fases sólida, líquida e gasosa mas, embora útil para alguns propósitos, este conceito não caracteriza uma região química, fisicamente homogênea e mecanicamente separável, entendida pela termodinâmica como fase.

Estas considerações não só explicam a ausência de critérios para aplicação de parâmetros termodinâmicos em sistemas heterogêneos como o solo ${ }^{25,26}$, como também respaldam a preferência por minerais puros em experimentos que envolvem reações de adsorção (Tabela 3). Ademais, a comparação entre os resultados termodinâmicos para reações de adsorção, compilados da literatura, precisa levar em consideração que os valores dependerão do modelo de adsorção selecionado ${ }^{50}$, uma vez que ainda não há um método ideal para aquisição destes parâmetros para sistemas heterogêneos, como o solo ${ }^{25}$.

Tabela 3. Variação da energia livre $(\Delta \mathrm{G})$ da reação de adsorção de alguns elementos por diferentes superfícies

\begin{tabular}{|c|c|c|c|}
\hline Adsorvente & Adsorvato & $\begin{array}{c}\Delta \mathrm{G} \\
\mathrm{KJ}^{\mathrm{mol}}{ }^{-1}\end{array}$ & Ref. \\
\hline \multicolumn{4}{|c|}{ Sistemas heterogêneos } \\
\hline \multirow[t]{3}{*}{ Latossolos ácricos } & herbicida & $+3,5$ & 57 \\
\hline & $\mathrm{Cd}$ & $-2,5$ & 32 \\
\hline & $\mathrm{Cu}$ & $-10,0$ & 31 \\
\hline \multirow[t]{6}{*}{ Latossolos argilosos } & $\mathrm{B}$ & $-1,0$ & 39 \\
\hline & $\mathrm{Cu}$ & $-16,7$ & 25 \\
\hline & $\mathrm{Cd}$ & $-17,8$ & \\
\hline & $\mathrm{Pb}$ & $-24,0$ & \\
\hline & $\mathrm{Zn}$ & $-14,6$ & \\
\hline & $\mathrm{Hg}$ & $-11,5$ & \\
\hline \multicolumn{4}{|c|}{ Sistemas puros } \\
\hline Óxido de alumínio ativado & As(III) & $-33,1$ & 35 \\
\hline \multirow[t]{2}{*}{ Óxido de alumínio (sintetizado) } & $\mathrm{Cd}$ & $-22,18$ & 11 \\
\hline & $\mathrm{Zn}$ & $-21,21$ & \\
\hline \multirow[t]{2}{*}{ Óxido de ferro (sintetizado) } & $\mathrm{Cd}$ & $-19,41$ & \\
\hline & $\mathrm{Zn}$ & $-20,50$ & \\
\hline \multirow[t]{2}{*}{ Óxido de manganês (sintetizado) } & $\mathrm{Cd}$ & $-29,16$ & \\
\hline & $\mathrm{Zn}$ & $-30,54$ & \\
\hline Ferrihidrita & $\mathrm{Zn}(\mathrm{II})$ & $-22,6$ & 13 \\
\hline \multirow[t]{2}{*}{ Montmorilonita } & $\mathrm{Cu}$ & $+77,1$ & 62 \\
\hline & $\mathrm{B}$ & $-0,6$ & 29 \\
\hline Caulinita & B & $-0,6$ & 29 \\
\hline \multicolumn{4}{|c|}{ Superfícies orgânicas } \\
\hline $\begin{array}{l}\text { Farelo de trigo desidratado } \\
\text { (FTD) }\end{array}$ & $\mathrm{Cu}(\mathrm{II})$ & $-25,1$ & 54 \\
\hline $\begin{array}{l}\text { Microrganismos } \\
\text { (Chlorella vulgaris) }\end{array}$ & $\mathrm{Ni}(\mathrm{II})$ & $-0,7$ & 28 \\
\hline
\end{tabular}

Como normalmente a fase líquida também não se enquadra na exigência de homogeneidade, admite-se que o sistema sólido-solução, cuja interface é de interesse por sediar as reações químicas que governam a geodisponibilidade dos elementos, esteja num constante estado de falta de equilíbrio. Porém, este aparente desequilíbrio não implica o abandono das bases termodinâmicas, cujos princípios permitem determinar quais processos são mais energeticamente favoráveis, mesmo em sistemas dinâmicos como o solo ${ }^{26}$.

Apesar de o solo ser considerado um sistema complexo, sua composição mineral torna-se mais simplificada quando exposto a prolongadas condições de temperatura e umidade altas. Condições extremas de intemperização intensificam a dessilicatização e favorecem o acúmulo de óxidos de $\mathrm{Fe}$ e $\mathrm{Al}$, que caracteriza o material ácrico ${ }^{51}$. As cargas elétricas desenvolvem-se sobre a superfície destes minerais, ou pela dissociação de íons $\mathrm{H}^{+}$dos grupos hidroxilados de superfície, ou pela combinação destes grupos com íons $\mathrm{H}^{+}$presentes na solução ${ }^{52}$ :

$\mathrm{M}-\mathrm{OH}_{2} \underset{+\mathrm{H}^{+}}{\stackrel{-\mathrm{H}^{+}}{\rightleftarrows}} \mathrm{M}-\mathrm{OH} \underset{+\mathrm{H}^{+}}{\stackrel{-\mathrm{H}^{+}}{\rightleftarrows}} \mathrm{M}-\mathrm{O}^{-}$ (reação 1)

em que $\mathrm{M}$ representa um metal que pode ser $\mathrm{Fe}$ ou $\mathrm{Al}$, gerando os grupos Fe-OH ou Al-OH. O comportamento anfótero, ou seja, a 
capacidade de reversibilidade de cargas, é característico dos óxidos do solo, porque a perda ou a incorporação de um íon $\mathrm{H}^{+}$pode tornar sua superfície carregada negativa ou positivamente.

Muitos poliânions podem ser formados na solução do solo a partir do ácido bórico, de acordo com a seguinte reação ${ }^{53}$ :

$$
\mathrm{mH}_{3} \mathrm{BO}_{3}^{0}=\left(\mathrm{H}_{3} \mathrm{BO}_{3}\right)_{\mathrm{m}}^{0}
$$

cujo produto se dissocia em:

$$
\left(\mathrm{H}_{3} \mathrm{BO}_{3}\right)_{\mathrm{m}}^{0} \rightleftarrows\left(\mathrm{H}_{3} \mathrm{BO}_{3}\right)_{\mathrm{m}-1}^{0}\left(\mathrm{H}_{2} \mathrm{BO}_{3}\right)^{-}+\mathrm{H}^{+}
$$

A termodinâmica da formação de espécies de boro em solução aquosa oferece diversas constantes de equilíbrio para hidrólise do ácido bórico e conseqüente formação de poliânions ${ }^{53}$. Em sistemas naturais, especialmente quando a concentração total de boro dissolvido é muito baixa, a formação dessas espécies de boro pode ser desprezada porque os íons alcançam um novo equilíbrio instantaneamente, e os poliânions são dissociados a ácido bórico ou a monoboratos ${ }^{3}$. Em solução, o ácido bórico comporta-se como um ácido fraco de Lewis, cuja primeira reação de hidrólise ocorre sob condições de $\mathrm{pH}$ acima de 9:

$$
\mathrm{B}(\mathrm{OH})_{3}^{0}+\mathrm{H}_{2} \mathrm{O} \stackrel{\mathrm{p}_{\mathrm{K}}=9,24}{\rightleftarrows} \mathrm{B}(\mathrm{OH})_{4}^{-}+\mathrm{H}^{+}
$$

(reação 4)

Estudos termodinâmicos da reação de adsorção geralmente contemplam todas as reações envolvidas, o que inclui a hidrólise na solução e a subseqüente adsorção dos produtos desta reação ${ }^{50}$. A descrição completa do sistema culmina com a interação entre a fase sólida e as espécies de boro presentes na fase líquida, que se estabelece pelo fenômeno da adsorção. O boro torna-se especificamente adsorvido na superfície de óxidos e de hidróxidos de $\mathrm{Fe}$ e $\mathrm{Al}$ por meio de troca de ligantes, situação em que o boro passa a atuar como uma base de Lewis, contrariamente ao seu comportamento em solução. Neste mecanismo, as espécies adsorvidas deslocam uma hidroxila ou uma molécula de água da superfície para formar ligações parcialmente covalentes ("inner-sphere”) com os cátions metálicos estruturais ${ }^{7,3}$ :

$$
\mathrm{SOH}_{(\mathrm{s})}+\mathrm{H}_{3} \mathrm{BO}_{3}{ }^{0} \text { (aq) } \rightleftarrows \mathrm{SH}_{2} \mathrm{BO}_{3}{ }^{0}(\mathrm{~s})+\mathrm{H}_{2} \mathrm{O}
$$

A abordagem termodinâmica de um sistema, em equilíbrio ou não, requer que as transformações por ele sofridas sejam mediadas por processos reversíveis. Entretanto, a reversibilidade é um conceito ideal que jamais pode ser alcançado porque, teoricamente, levaria um tempo infinito para ocorrer. A manifestação de cargas na superfície de colóides anfóteros, como os óxidos de Fe e Al, ocorre por processos reversíveis que dependem do $\mathrm{pH}$ da solução do solo. Não obstante, a natureza das espécies de boro que ocorrem na solução do solo também apresenta estreita dependência do $\mathrm{pH}$ do sistema. Dessa forma, os dois componentes do sistema solosolução, isto é, colóides e espécies de boro em solução, experimentam modificações de natureza reversível, pela influência do pH. Contudo, a reversibilidade da interação entre estes dois componentes ainda não é bem esclarecida, porque enquanto para alguns solos a isoterma de adsorção correspondeu à isoterma de dessorção $0^{45}$, em outros a dessorção de boro foi histerética ${ }^{54}$. O caráter histerético da adsorção de boro por solos pode estar relacionado à complexidade da fase sólida, porque a adsorção de boro por minerais puros, tais como a goethita ${ }^{4}$, e minerais de argila (caulinita, ilita e montmorilonita) ${ }^{41}$ foi não-histerética. A aparente irreversibilidade da reação de adsorção aniônica foi atribuída a vários mecanismos de adsorção, que incluem troca de ligantes, for- mação de complexos bidentados de superfície ou incorporação nas posições interlaminares dos minerais de argila ${ }^{7}$. No entanto, troca de ligantes é uma reação de adsorção reversível com respeito a mudanças no $\mathrm{pH}^{55}$ e, dessa forma, a reversibilidade da reação de adsorção de boro por solos com cargas variáveis atende às exigências da termodinâmica.

\section{Parâmetros termodinâmicos da reação de adsorção de boro}

\section{Fator de separação $\left(K_{R}\right)$}

Informações preliminares a respeito do grau de desenvolvimento e da espontaneidade da reação de adsorção podem ser obtidas a partir da avaliação do parâmetro de equilíbrio ou fator de separação $K_{R}$ (Equação 8), calculado a partir da constante $K$ de Langmuir (Equação 3). Segundo uma abordagem mais simplificada ${ }^{34,35}$, a adsorção é favorável e espontânea quando $K_{R}<1$, enquanto valores de $K_{R}>1$ indicam falta de espontaneidade da reação. O coeficiente $K_{R}$ pode indicar ainda se a isoterma de adsorção é desfavorável ao processo $\left(K_{R}>1\right)$, linear $\left(K_{R}=1\right)$, favorável $\left(0<K_{R}<1\right)$ ou irreversível $\left(K_{R}=0\right)^{33}$. Os valores de $K_{R}$ para a reação de adsorção de boro, sob condições naturais de $\mathrm{pH}$, estiveram entre 0 e $1 \mathrm{e}$, portanto, a adsorção de boro foi favorecida em todos os solos, independentemente da profundidade, na seguinte ordem: NV>LA $>$ LV (Figura 2).
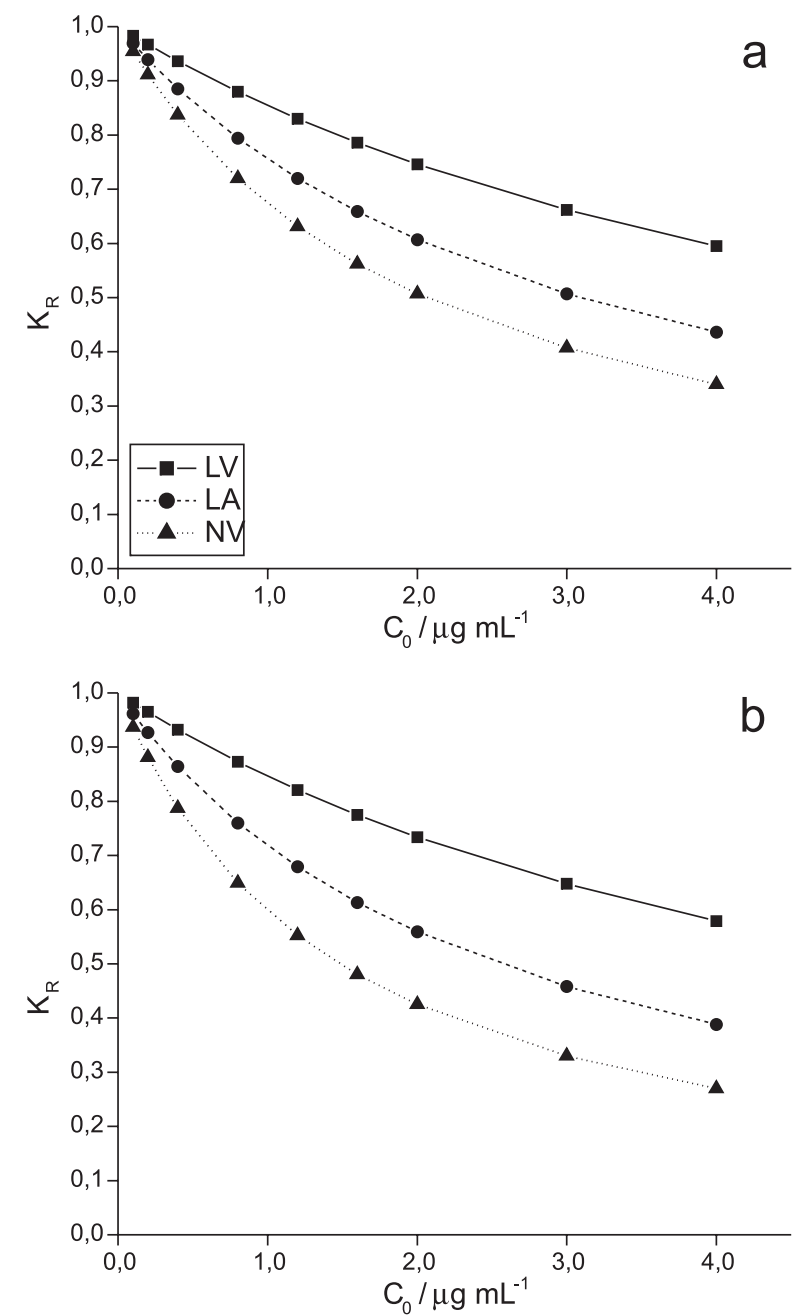

Figura 2. Variação nos valores do fator de separação $\left(K_{R}\right)$ em função da concentração de boro adicionada aos solos $\left(C_{0}\right) ; a=$ amostras superficiais; $b=$ amostras subsuperficiais $; L V=$ Latossolo Vermelho; $L A=$ Latossolo Amarelo; $N V=$ Nitossolo Vermelho 
Valores de $K_{R}$ que variaram de 0,105 a 0,119 foram anteriormente reportados para a adsorção de ânions arseniato por superfícies oxídicas, cuja reação foi considerada extremamente favorá$\mathrm{vel}^{35}$. Os menores valores de $K_{R}$ foram obtidos com a adição de maiores quantidades de boro e estão de acordo com alguns resultados obtidos para as reações de cátions metálicos com superfícies orgânicas ${ }^{33,55}$. Isto indicou que a adsorção foi mais favorável para altas concentrações iniciais $\left(C_{o}\right)$ de boro que para as mais baixas. O parâmetro $K_{R}$ é sensível ao raio hidratado dos íons ${ }^{56}$ mas, nas condições de $\mathrm{pH}$ em que o experimento se desenvolveu, o boro está predominantemente na forma molecular neutra de ácido bórico. Além disso, o mecanismo de adsorção de boro é do tipo específico e não admite a interposição de moléculas de água na interface sólido-solução. Estes argumentos justificam as expectativas por baixos valores de $K_{R}$ para a adsorção de boro.

A adsorção de fluoreto por resíduo à base de argila montmorilonítica foi caracterizada pelo valor $K_{R}=0,459$, após a adição de $20 \mathrm{mg} \mathrm{L}^{-1}$ do elemento ${ }^{34}$. Este resultado pode ser usado como referência, porque o fluoreto é um ânion de comportamento químico muito semelhante ao do boro e que reage com vários minerais do solo, tais como goethita, gibbsita e caulinita, pelo mecanismo de troca de ligantes com grupos $\mathrm{OH}$ coordenados ${ }^{57}$. Os valores de $K_{R}$ das amostras dos Latossolos ácricos variaram de 0,388 a 0,579 e estiveram bem próximos daquele obtido para fluoreto ${ }^{34}$. A comparação quantitativa permite admitir que os solos ácricos são sistemas mais favoráveis à adsorção de boro que a argila montmorilonítica é para a adsorção de fluoreto, porque foi necessária a adição de uma quantidade cinco vezes maior de fluoreto para que os valores de $K_{R}$ se assemelhassem. Isso pode ser atribuído à maior reatividade de sistemas oxidícos e cauliníticos para reações de troca de ligantes, quando comparados a sistemas montmoriloníticos. Os valores de $K_{R}$ foram menores para as amostras subsuperficiais, indicando que a adsorção de boro desenvolveu-se mais espontaneamente na ausência da matéria orgânica, ao contrário do que é reportado para cátions metálicos, cujos valores de $K_{R}$, tendendo a zero, indicaram que a adsorção destes elementos por superfícies orgânicas pode tender à irreversibilidade ${ }^{33,55}$.

\section{Variação da energia livre da adsorção de boro $(\Delta G)$}

$\mathrm{Na}$ maioria dos estudos, a adsorção é modelada em função da temperatura, para obtenção da entalpia ${ }^{25}$. A diminuição da adsorção com o aumento da temperatura é típica de ânions em superfícies minerais. Há relatos de que a adsorção de boro por superfícies oxídicas e silicatadas foi maior a $10{ }^{\circ} \mathrm{C}$ que a 25 e $40{ }^{\circ} \mathrm{C}$, o que aponta para a natureza exotérmica da adsorção específica de boro ${ }^{7}$. No entanto, alguns trabalhos com metais pesados mostraram que o mecanismo de adsorção, assim como a intensidade do processo (medido pelo parâmetro $\mathrm{q}_{\text {máx }}$ de Langmuir) foi pouco alterado com a temperatura, e geralmente qualquer conclusão feita acerca do fenômeno a $25^{\circ} \mathrm{C}$ aplica-se igualmente bem para outras temperaturas ${ }^{12}$.

Em experimentos de adsorção sem variação de temperatura não há variação da entalpia de ligação do adsorvato à superfície do adsorvente ${ }^{58}$. Dessa forma, é aceitável atribuir as variações da energia livre da reação apenas à variação da entropia $(\Delta S)^{59}$. Valores positivos de entropia sugerem alterações estruturais tanto da superfície do sorvente quanto do elemento adsorvido ${ }^{55}$. A reação 5 ilustra a possibilidade de tais alterações, justificadas pela natureza tipicamente covalente das ligações entre boro e solo, cuja energia de reação pode superar $200 \mathrm{~kJ}$ por $\mathrm{mol}^{11}$. Variações positivas da entropia implicam que a reação de adsorção requer uma redução da ordem do sistema. Diferenças de solvatação do adsorbato, sejam de suas espécies em solução ou das adsorvidas, assim como o próprio estado da água nas duas situações e a liberação de prótons para a solução ${ }^{50}$, podem ser causas da variação entrópica na adsorção. Dessa forma, parece razoável admitir que, em sistemas de cargas que variam com o $\mathrm{pH}$, os valores de entropia da adsorção de boro devam ser negativos, uma vez que a liberação de prótons para o sistema acarreta a diminuição do $\mathrm{pH}$, restringindo a adsorção de boro.

A $\Delta \mathrm{G}$ indica o grau de espontaneidade do processo de adsorção, e os mais altos valores (em módulo) refletem uma reação de adsorção mais energeticamente favorável ${ }^{55}$. A reação de adsorção de elementos metálicos por superfícies orgânicas e inorgânicas de sistemas puros ou isolados geralmente é espontânea (Tabela 3). A espontaneidade da reação de adsorção de cádmio ${ }^{32}$ e cobre $^{31}$ por solos intemperizados, assim como a de $\mathrm{Cd}$ e $\mathrm{Zn}$ por superfícies oxídicas sintéticas ${ }^{11}$, foi caracterizada por valores negativos da energia livre da reação. Valores negativos para a mudança da energia livre da reação de adsorção $\mathrm{Cu}, \mathrm{Ni}, \mathrm{Pb}$ e $\mathrm{Cd}$ por magnetita também foram observados ${ }^{56}$.

No entanto, variações que dependem da natureza do elemento e da superfície do adsorvente podem indicar um processo não-espontâneo, caracterizado por valores positivos de $\Delta \mathrm{G}$, como aqueles encontrados para a adsorção de Co e herbicida imazaquin por so$\operatorname{los}^{27,58}$ (Tabela 3). Neste trabalho, os valores negativos de $\Delta \mathrm{G}$ confirmaram a viabilidade e a natureza espontânea da adsorção de boro (Tabela 2) e corroboraram resultados anteriormente obtidos em solos altamente intemperizados ${ }^{30}$.

Quando se consideram doses crescentes do elemento adicionadas ao solo, o valor de $\Delta \mathrm{G}$ pode revelar a magnitude da extensão de reação entre o elemento e a superfície do adsorvente ${ }^{31}$. Assim, valores negativos de $\Delta \mathrm{G}$ implicam que a reação deva estar ocorrendo na direção da formação de produtos, ou seja, no sentido de ocorrer adsorção. Quanto mais negativa a $\Delta \mathrm{G}$, maior é a força motriz para que a adsorção ocorra. Por outro lado, a diminuição de seu valor com a concentração inicial do adsorbato pode significar que a força (ou energia) de interação com o adsorvente seja fraca e que reações de adsorção podem ser favorecidas a partir de seu aumento $^{28}$. O decréscimo da energia livre da reação de adsorção de $\mathrm{Cu}$ e Cd por solos altamente intemperizados com o aumento da concentração levaram à conclusão de que quanto mais concentrada a solução, menos fortemente os elementos foram adsorvidos ${ }^{31,32}$. Apesar do mesmo comportamento para a adsorção de boro ter sido notado anteriormente ${ }^{39}$, neste trabalho, tal tendência não foi observada. Como mostraram as isotermas do tipo " $C$ " (Figura 1), as baixas concentrações inicialmente adicionadas podem não ter sido capazes de saturar os sítios de adsorção. Entretanto, para todas as amostras e concentrações, os valores de $\Delta \mathrm{G}$ foram negativos e, além da espontaneidade da reação, isto indica que as formas sorvidas são mais estáveis que aquelas em solução ${ }^{58}$.

A Tabela 2 mostra a variação da energia livre de adsorção, com o aumento do $\mathrm{pH}$, após a adição de $2 \mathrm{mg} \mathrm{L}^{-1}$ de boro. Houve elevação dos valores de $\Delta \mathrm{G}$ com o aumento do $\mathrm{pH}$, em todas amostras, assim como relatado em outros trabalhos para adsorção de boro ${ }^{30} \mathrm{e}$ de herbicida imazaquin ${ }^{58}$ por solos intemperizados. $\mathrm{Na}$ amostra superficial do LV, a elevação de três unidades de $\mathrm{pH}$ ocasionou aumento de três vezes na energia livre da adsorção de boro. As maiores variações de energia livre de adsorção de boro ocorreram no NV, principalmente quando o $\mathrm{pH}$ foi alto (Tabela 2). Entretanto, não houve correlação significativa entre $\mathrm{pH}$ e $\Delta \mathrm{G}$, o que confirmou a tendência já observada de que o efeito isolado do $\mathrm{pH}$ do solo na energia livre parece ser relativamente baixo em solos ácidos ${ }^{30}$. A correlação não significativa da energia livre com o $\mathrm{pH}$, na faixa de reação ácida, pode ser devida ao fato do elemento estar predominantemente na forma de ácido bórico, e não na sua forma aniônica $\mathrm{H}_{2} \mathrm{BO}_{3}^{-}$. Em pH 6,5, ou seja, próximo à neutralidade, somente $0,4 \%$ 
do boro em solução está na forma aniônica ${ }^{9}$. A adsorção do elemento sob condições ácidas reforça que o fenômeno parece ser resultado da adsorção molecular do ácido bórico.

A energia livre da reação de adsorção é composta por três componentes $^{61}: \Delta \mathrm{G}_{\text {coul }}$, componente eletrostático ou coulômbico; $\Delta \mathrm{G}_{\text {quimm }}$, componente químico; e $\Delta \mathrm{G}_{\mathrm{int}}$, componente de interação, o qual dá mais especificidade ao componente eletrostático, ou seja:

$\Delta \mathrm{G}_{\text {ads }}=\Delta \mathrm{G}_{\text {coul }}+\Delta \mathrm{G}_{\text {quim }}+\Delta \mathrm{G}_{\text {int }}$

Sendo assim, em sistemas com cargas elétricas variáveis, como é o caso dos Latossolos ácricos LV e LA, em que ânions normalmente são especificamente adsorvidos, $\Delta \mathrm{G}_{\text {quim }}$ é o componente mais importante, seguido distantemente pelo componente $\Delta \mathrm{G}_{\text {coul }}{ }^{57}$. A adsorção específica ocorre porque a energia de adsorção é suficientemente grande para dissociar o ácido na superfície do adsorvente. Se a energia livre de adsorção do ânion é constante, independentemente do $\mathrm{pH}$, então ela estará disponível para remover o $\mathrm{H}^{+}$do ácido indissociado. Porém, a energia requerida para este processo varia com o pH, o que explica a variação da adsorção aniônica em função do $\mathrm{pH}$ do meio ${ }^{62}$.

De maneira geral, quando comparados sob as mesmas condições de $\mathrm{pH}$, os valores de $\Delta \mathrm{G}$ foram maiores na camada superficial do LV e do NV (Tabela 2) e este fato parece reforçar o efeito da matéria orgânica na adsorção de boro (Tabela 1). A adsorção pela matéria orgânica também pode ser específica, ocorrendo pelo mecanismo de troca de ligantes com grupos funcionais, como carbonil, hidroxil e fenol ${ }^{25}$. Já para o LA, os valores de $\Delta \mathrm{G}$ foram maiores em subsuperfície (Tabela 2), onde a superfície exposta da fração inorgânica é maior, em função dos menores teores de matéria orgânica. Apesar do menor teor de argila (Tabela 1), o LA apresentou valores de $\Delta \mathrm{G}$ equivalentes àqueles observados para o NV. A adsorção de boro nos Latossolos é governada pela densidade de cargas variáveis (Tabela 1). Estudos sobre a adsorção de $\mathrm{Cd}$ e Co pela caulinita revelaram que a entalpia nos sítios de carga variável alcançou $70 \mathrm{~kJ}$, ou seja, uma quantidade de energia sete vezes superior quando comparada aos sítios de cargas permanentes ${ }^{12}$.

Dentre os Latossolos, o LA apresentou maiores valores de $\Delta \mathrm{G}$, quando avaliados no mesmo valor de $\mathrm{pH}$. O LA apresentou o maior teor de Al extraído por solução DCB-Na. O Al decorrente desta extração é proveniente da dissolução dos óxidos de ferro e representa o alumínio que, isomorficamente, substituiu o ferro na estrutura cristalina destes minerais. Quanto maior o grau de substituição de $\mathrm{Fe}$ por $\mathrm{Al}$, mais desordenada está a estrutura cristalina do mineral, o que gera aumento da área superficial específica e aumenta a reatividade dos óxidos para reações de adsorção. Os valores de $\Delta \mathrm{G}$ entre os Latossolos foram equivalentes somente sob condições muito distintas de $\mathrm{pH}$ (Tabela 2). Os resultados para a energia livre de adsorção de boro variaram entre 660 e $1292 \mathrm{~J} \mathrm{~mol}^{-1}$ nos Latossolos e estão de acordo com resultados anteriormente encontrados para solos semelhantes ${ }^{30}$.

A adsorção de boro foi mais favorecida no NV, como mostraram os altos valores de $\Delta \mathrm{G}$ (Tabela 2). Os maiores teores de matéria orgânica, assim como a maior superfície específica dos minerais 2:1 interestratificados (não mostrados) do NV (Tabela 1), podem ter otimizado o contato do boro presente em solução com a superfície adsorvente, apesar de aparentemente não haver diferenças entre os valores de $\Delta \mathrm{G}$ para adsorção de boro pela caulinita e pela montmorilonita ${ }^{29}$ (Tabela 3 ).

$\mathrm{O} \Delta \mathrm{G}$ varia em função das concentrações iniciais de reagentes e de produtos, o que torna difícil a comparação de muitas reações. No entanto, as condições sob as quais este experimento foi realiza- do permitem tal comparação porque as quantidades iniciais dos reagentes (solo e soluções contendo boro) são conhecidas. A relação entre $\Delta \mathrm{G}$ e a constante de equilíbrio $\mathrm{K}_{\text {eq }}$, para condições naturais de $\mathrm{pH}$ e após a adição de $2 \mathrm{mg} \mathrm{L}^{-1}$ de boro, é mostrada na Figura 3.

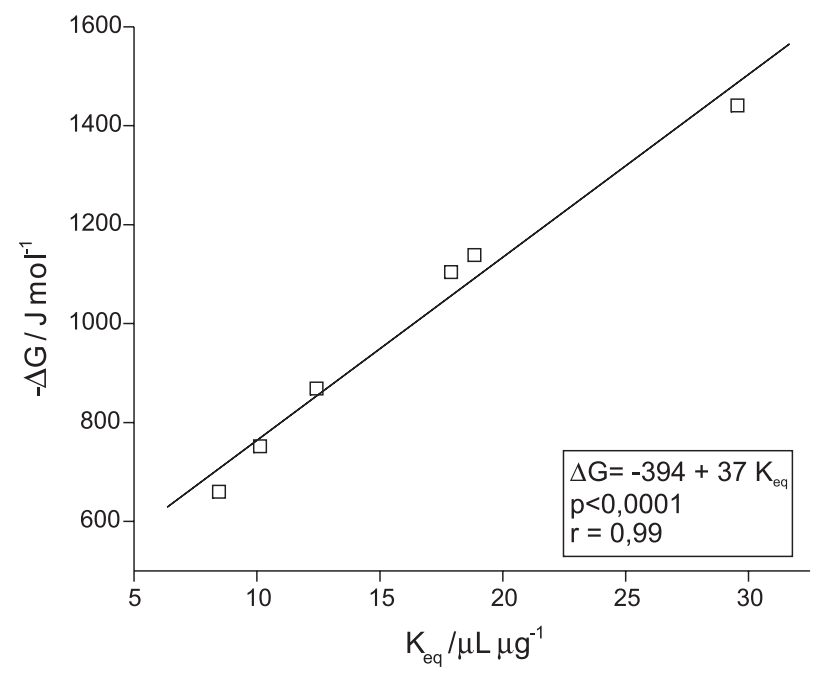

Figura 3. Relação entre a constante de equilíbrio $\left(K_{e q}\right)$ e a variação da energia livre $(\Delta G)$ da reação de adsorção de boro em amostras naturais (sem alteração do $\mathrm{pH}$ ) coletadas nas camadas superficiais e subsuperficiais de três solos intemperizados

Nota-se que quanto maior o valor de $\mathrm{K}_{\text {eq }}$, maior será a energia liberada até que o equilíbrio seja atingido. Os valores de $\mathrm{K}_{\mathrm{eq}}$ indicaram que, após a reação, restarão mais produtos (formas adsorvidas) que reagentes, e esta situação foi confirmada por valores negativos de $\Delta \mathrm{G}$, ou seja, a reação 5 se processará espontaneamente para a direita.

\section{CONCLUSÕES}

A equação de Langmuir simulou adequadamente os resultados de boro adsorvido. Os maiores valores de adsorção máxima $\left(\mathrm{q}_{\max }\right)$ foram encontrados nas amostras superficiais dos solos e evidenciaram a influência da matéria orgânica na retenção do boro. Entretanto, o boro apresentou maior afinidade pelas amostras subsuperficiais, como indicado pelos altos valores da constante $\mathrm{K}$ de Langmuir. A adsorção de boro por solos altamente intemperizados foi dependente do $\mathrm{pH}$, sobretudo em função do caráter anfótero dos seus constituintes minerais, e da concentração do elemento. O boro foi adsorvido pelos solos por reações energeticamente favoráveis e espontâneas em toda a faixa de concentração e pH estudados. O trabalho realizado para adsorção de boro foi refletido pelos valores da variação da energia livre $(\Delta G)$, cujo sinal negativo indicou a natureza exergônica da reação, com liberação de energia para conversão das formas menos estáveis de boro em solução em formas adsorvidas com maior estabilidade. Com o aumento do $\mathrm{pH}$, a $\Delta \mathrm{G}$ tornou-se mais negativa como resultado do aumento da força motriz para ocorrência da reação de adsorção. Os resultados da variação da energia livre, do fator de separação $\left(K_{R}\right)$ e da constante de afinidade de Langmuir foram indicativos importantes de que a retenção de boro por solos intemperizados ocorre por mecanismos de adsorção específica, principalmente com o aumento do $\mathrm{pH}$ das camadas mais profundas do perfil do solo. 


\section{AGRADECIMENTOS}

À FAPESP pela concessão de bolsa ao primeiro autor (processo n. $98 / 02386-1)$

\section{REFERÊNCIAS}

1. Mengel, K.; Kirkby, E. A.; Principles of Plant Nutrition, Kluwer Academic Publishers: Dordrecht, 2001.

2. Goldberg, S.; Plant Soil 1997, 193, 35.

3. Keren, R.; Bingham, F. T.; Adv. Soil Sci. 1985, 1, 229.

4. Bloesch, P. M.; Bell, L. C.; Hughes, J. D.; Aust. J. Soil Res. 1987, 25, 377.

5. Woods, W. G.; Environ. Health Perspect. 1994, 102, 5.

6. Gupta, U. C.; Jame, Y. W.; Campbell, C. A.; Leyshon, A. J.; Nicholaichuk, W.; Can. J. Soil Sci. 1985, 65, 381.

7. Goldberg, S.; Forster, H. S.; Heick, E. L; Soil Sci. Soc. Am. J. 1993, 57, 704.

8. Peak, D.; Luther, G. W.; Sparks, D. L.; Geochim. Cosmochim. Acta 2003, 67, 2551.

9. Evans, L. J.; Can. J. Soil Sci. 1987, 67, 33.

10. Goldberg, S.; Glaubig, R. A.; Soil Sci. Soc. Am. J. 1985, 49, 1374.

11. Trivedi, P.; Axe, L.; Environ. Sci. Technol. 2000, 34, 2215.

12. Angove, M. J.; Johnson, B. B.; Wells, J. D.; J. Colloid Interface Sci. 1998, 204, 93.

13. Trivedi, P.; Dyer, J.A.; Sparks, D. L.; Pandya, K.; J. Colloid Interface Sci. 2004, 270, 77.

14. Alleoni, L. R. F.; Camargo, O. A.; R. Bras. Ci. Solo 1994, 18, 175.

15. Casagrande, J. C.; Camargo, O. A.; R. Bras. Ci. Solo 1997, 21, 353.

16. Camargo, O. A.; Moniz A. C.; Jorge, J. A.; Valadares, J. M. A. S.; Métodos de análise química, mineralógica e física de solos do Instituto Agronômico de Campinas (Bol. Téc. 106): Campinas, 1986.

17. van Raij, B.; Andrade, J. C. de; Cantarella, H.; Quaggio, J.A.; Análise química para avaliação da fertilidade de solos tropicais, Instituto Agronômico de Campinas: Campinas, 2001.

18. Mekaru, T.; Uehara, G.; Soil Sci. Soc. Am. Proc. 1972, 36, 296.

19. Anderson, S. J.; Sposito, G.; Soil Sci. Soc. Am. J. 1991, 55, 1569

20. Gee, G. W.; Bauder, J. W. Em Methods of Soil Analysis: Part 4 - Physical Methods; Dane, J.H.; Toop, G.C., eds.; SSSA: Madison, Book Series n.5, 2002 , cap. 15

21. Feller, C.; Schouller, E.; Thomas, F.; Rouiller, J.; Herbillon, A. J.; Soil Sci. 1992, 153, 293.

22. Tan, K. H.; Hajek, B. F.; Barshad, I. Em Methods of Soil Analysis: Part 1 - Physical and Mineralogical Methods; Klute, A., ed.; SSSA: Madison, $2^{\text {nd }}$ ed. 1986, cap. 7.

23. Wolf, B.; Soil Sci. Plant Anal. 1971, 2, 363.

24. Barrow, N. J.; Reactions with variable-charge soils, Martinus Nijhoff Publishers: Dordrecth, 1987.

25. Airoldi, C.; Critter, S. A. M.; Clays Clay Miner. 1997, 45, 125.

26. Suarez, D. L. Em Soil physical chemistry; Sparks, D.L., ed.; CRC Press: Boca Raton, 1999, cap. 3.
27. Rawat, J. P.; Iraqi, S. M. U.; Singh, R. P.; Colloids Surf., A 1996,117, 183. 28. Aksu, Z.; Process Biochem. 2002, 38, 89.

29. Singh, M.; Geoderma 1971, 5, 209.

30. Alleoni, L.R.F.; Camargo, O.A.; R. Agric. 1998, 73, 319.

31. Silveira, M.L.A.; Alleoni, L.R.F.; Casagrande, J.C.; Camargo, O.A.; Sci. Agric. (Piracicaba, Braz.) 1999, 56, 1117

32. Dias, N.M.P.; Alleoni, L.R.F.; Casagrande, J.C.; Camargo, O.A.; Ci. Rural 2003, 33, 829 .

33. Ho, Y.S.; Huang, C.T.; Huang, H.W.; Process Biochem. 2002, 37, 1421.

34. Mahramanliouglu, M.; Kizilcikli, I.; Bicer, I.O.; J. Fluorine Chem. 2002,115, 41.

35. Singh, T. S.; Pant, K. K.; Sep. Purif. Technol. 2004, 36, 139

36. Alves, M. E.; Lavorenti, A.; Geoderma 2004, 118, 89.

37. Empresa Brasileira de Pesquisa Agropecuária; Sistema Brasileiro de Classificação de Solos, EMBRAPA: Rio de Janeiro, 1999.

38. Evans, C. M.; Sparks, D. L.; Commun. Soil Sci. Plant Anal. 1983, 14, 827.

39. Alleoni, L. R. F.; Camargo, O. A.; Casagrande, J. C.; Sci. Agric. (Piracicaba, Braz.) 1998, 55, 379.

40. Giles, C. H.; Smith, D.; Huitson, A.; J. Colloid Interface Sci. 1974, 47, 755.

41. Keren, R.; Gast, R. G.; Soil Sci. Soc. Am. J. 1983, 47, 1116.

42. Goldberg, S.; Forster, H.S.; Soil Sci. 1991, 152, 304.

43. Hartcher, J. T.; Bower, C. A.; Soil Sci. 1958, 85, 319

44. Hadas, A.; Hagin, J.; Soil Sci. 1972, 113, 189.

45. Elrashidi, M. A.; O’Connor, G. A.; Soil Sci. Soc. Am. J. 1982, 46, 27.

46. Gu, B.; Lowe, L. E.; Can. J. Soil Sci. 1990, 70, 305.

47. Mezuman, U.; Keren, R.; Soil Sci. Soc. Am. J. 1981, 45, 722

48. Goldberg, S.; Glaubig, R. A.; Soil Sci. Soc. Am. J. 1986, 50, 1442.

49. Alleoni, L. R. F.; Camargo, O. A.; Pesq. Agropec. Bras. 2000, 15, 413.

50. Rodda, D. P.; Johnson, B. B.; Wells, J. D.; J. Colloid Interface Sci. 1996 $184,365$.

51. Alleoni, L. R. F.; Camargo, O. A.; Bol. Inf. Soc. Bras. Ci. Solo 1995, 20, 9.

52. Zhang, X. N.; Zhao, A. Z. Em Chemistry of variable charge soils; Yu, T.R., ed.; Oxford University Press: New York, 1997, cap. 2.

53. Basset, R. L.; Geochim. Cosmochim. Acta 1980, 44, 1151

54. Okasaki, E.; Chao, T.T.; Soil Sci. 1968, 105, 255.

55. Özer, A.; Özer, D.; Özer, A.; Process Biochem. 2004, 39, 2183.

56. Ortiz, O.; Tese de Doutorado; Instituto de Pesquisas Energéticas e Nucleares, Brasil, 2000.

57. Partiff, R. L.; Adv. Agronomy 1978, 30, 1.

58. Rocha, W. S. D.; Alleoni, L.R.F.; Regitano, J.B.; R. Bras. Ci. Solo 2003, 27, 239.

59. Baham, J.; Sposito, G.; J. Environ. Qual. 1994, 23, 147.

60. Klotz, I. M.; Rosenberg, R. M.; Chemical thermodynamics: basic, theory and methods, Benjamin/Cummings Pub.Co: Menlo Park, 1986.

61. Bowden, J. W.; Posner, A. M.; Quirk, J. P.; Aust. J. Soil Res. 1977, 15, 121.

62. Hingston, F. J.; Posner, A. M.; Quirk, J. P.; J. Soil Sci. 1972, 23, 177. 